\title{
Perceptions of harm from secondhand smoke exposure among U.S. adults, 2009-2010
}

\author{
Judy Kruger ${ }^{1 *}$, Roshni Patel ${ }^{2}$, Michelle Kegler ${ }^{3}$, Steven D. Babb and Brian A. King ${ }^{1}$
}

\begin{abstract}
Background: Exposure to secondhand smoke (SHS) causes significant disease and death. We assessed the prevalence and correlates of perceptions about the health harm of SHS among U.S. adults at the national and state level.

Methods: Data came from the 2009-2010 National Adult Tobacco Survey, a national landline and cellular telephone survey. Perceptions about the health harms of SHS were assessed as follows: 'not at all harmful', 'somewhat harmful', and 'very harmful'. Descriptive statistics were used to assess the prevalence of SHS harm perceptions by tobacco use and sociodemographic factors, including sex, age, race/ethnicity, education, marital status, annual household income, region, sexual orientation, children in the household, and smoke-free law coverage. Logistic regression was used to assess odds of perceiving SHS to be "very harmful" (vs. "not at all harmful" or "somewhat harmful"), adjusting for the aforementioned factors.
\end{abstract}

Results: Nationally, $64.5 \%$ of adults perceived SHS as 'very harmful' (state range: $73.5 \%$ [Utah] to $53.7 \%$ [Kentucky]). By tobacco use, the perception that SHS is 'very harmful' was: $76.5 \%$ among nonusers of tobacco; $62.1 \%$ among noncombustible only users; $47.9 \%$ among combustible only users; and $40.8 \%$ among dual combustible and noncombustible users. Following adjustment, the perception that SHS was 'very harmful' was higher among females, non-Hispanic minorities and Hispanics, respondents living with children, and states with $100 \%$ smoke-free law coverage. Among current tobacco users the odds of perceiving SHS to be 'very harmful' was lower in the Midwest than the West.

Conclusions: Almost two-thirds of American adults perceive SHS as 'very harmful'; however, currently only half of all Americans are protected by comprehensive state or local smoke-free laws. These findings underscore the importance of public education campaigns to increase awareness of SHS exposure harm and the benefits of smoke-free environments. Expanding comprehensive smoke-free laws could protect all Americans from SHS.

Keywords: Tobacco, Smoking, Policy, Secondhand smoke

\section{Background}

Secondhand smoke (SHS) exposure causes heart disease, stroke, and lung cancer in nonsmoking adults, and sudden infant death syndrome, acute respiratory infections, middle ear infections, and more severe asthma in children [1]. SHS exposure causes more than 41,000 deaths among U.S. nonsmokers each year, costing the country an estimated $\$ 5.6$ billion annually [2]. The U.S. Surgeon

\footnotetext{
* Correspondence: ezk0@cdc.gov

'Office on Smoking and Health, National Center for Chronic Disease Prevention and Health Promotion, Centers for Disease Control and Prevention, Atlanta, GA, USA

Full list of author information is available at the end of the article
}

General has concluded that there is no risk-free level of SHS exposure, and that eliminating smoking in indoor spaces is the only way to fully protect nonsmokers from SHS exposure [1]. Over the past two decades, substantial progress has been achieved in implementing comprehensive smoke-free laws prohibiting smoking in all indoor workplaces and public places, including restaurants and bars, at both the local and state levels. Across the U.S., the number of local level comprehensive smokefree laws increased from two in 1993 to more than 600 in 2014, while the number of statewide laws increased from one in 2002 to 26 and the District of Columbia in 
2014 [3, 4]. However, while adoption of local level comprehensive smoke-free laws continues, the adoption of statewide laws has stalled in recent years and residents of 24 states remain unprotected by such laws and, thus, are susceptible to SHS exposure in many indoor public spaces [5]. Approximately 58 million Americans, including 15 million children, continue to be exposed to SHS [6].

Research on public perception toward the harmful effects of SHS is growing $[7,8]$ and studies have revealed that sociodemographic correlates may contribute to harm perception [2] and the use of noncombustible tobacco products [9-11]. Levels of support for smoke-free public places have been shown to vary by cigarette smoking status, experience with smoke-free environments, knowledge about the harmfulness of SHS exposure, and other factors [12-18]. Changes in attitudes about the acceptability of SHS exposure and the benefits of smoke-free environments both contribute to, and are further accelerated by, the publicity, education, debate, and experiences that generally accompany the adoption of smoke-free laws [1, 19]. State and local smoke-free laws typically receive high levels of public support, with this support increasing over time as people become accustomed to the protections afforded by these laws [20].

Awareness of the adverse health effects of SHS exposure is an especially important factor shaping public attitudes towards smoke-free policies [21]. Research indicates that increased knowledge about the harmfulness of SHS is associated with greater efforts to minimize exposure [22, 23], reduced SHS exposure among both smokers and nonsmokers [22-24], and adoption of smoke-free home rules [25, 26]. Increased awareness of the adverse health effects of SHS exposure is also associated with lower smoking initiation among youth [27] and more favorable attitudes toward smokefree environments [1, 19, 28].

Past research suggests that many U.S. adults recognize the dangers of SHS exposure. For example, using data from 2001, McMillen and colleagues reported that $95.1 \%$ of U.S. adults believed that inhaling smoke from a parent's cigarette caused any level of harm to infants and children, with lower prevalence among smokers (89.5 \%) than nonsmokers (96.7 \%) [13]. These findings were consistent with studies showing smokers are less likely to perceive that SHS exposure is harmful $[3,24]$. Similarly, a Gallup poll conducted during July 2014 found that $57 \%$ of U.S. adults viewed SHS as 'very harmful' [29]. However, to date, no published studies have assessed potential variations in perceived harm from SHS exposure comprehensively across states, tobacco use status, smoke-free law coverage, and certain sociodemographic factors. Thus, we assessed the prevalence and sociodemographic correlates of perceptions that exposure to SHS is 'very harmful' both overall and by state and tobacco use status among a nationally representative sample of U.S. adults.

\section{Methods \\ Sample}

Data came from the 2009-2010 National Adult Tobacco Survey (NATS), a national landline and cellular telephone survey of noninstitutionalized civilian adults aged 18 years or older residing in the 50 U.S. states and District of Columbia [30]. The study design has been described in detail elsewhere, including cognitive testing of the employed measures [31]. In brief, the 2009-2010 NATS used a stratified, multistage probability design to yield data representative at both the national and state levels. For the landline component, each state was allocated an equal target sample size $(n=1863)$ to ensure adequate precision for state estimates. For the cellular telephone component, each state was allocated a sample size in proportion to its population (range: 255-24,100). Louisiana, New Jersey, and Oklahoma added to their landline and cellular telephone target sample size; Delaware, Georgia, Iowa, North Dakota, Pennsylvania, South Carolina, and Virginia added to their landline target sample size.

The sample design consists of a dual frame Random Digit Dialed sample, with independent samples drawn from landline and cell phone fames [31]. Respondent selection varied by telephone type. For the landline numbers, one adult was randomly selected from each eligible household. For cellular telephone numbers, the adult reached was selected if a cellular telephone was the only way they could be reached at home. Interviews were administered from October 20, 2009 to February 28, 2010, and were conducted in both English and Spanish. In total, 118,581 interviews were conducted (landline = 110,634 and cellular $=7947$ ). The Council of American Survey and Research Organizations (CASRO) overall response rate, defined as the number of completed interviews divided by the number of eligible respondents in the sample, was $37.6 \%$ (landline $=40.4 \%$ and cellular $=$ $24.9 \%$ ) [32]. The overall cooperation rate, defined as the number of completed interviews divided by the number of eligible respondents who were successfully reached by an interviewer, was $62.3 \%$ (landline $=61.9 \%$ and cellular $=68.7 \%$ ) [32]. State-specific CASRO response rates ranged from 28.2 \% in New Jersey to $49.3 \%$ in Vermont, while cooperation rates ranged from $52.9 \%$ in Louisiana to $72.4 \%$ in Vermont.

\section{Measures}

\section{Harm perceptions}

Perceptions about the harm of SHS exposure were assessed by the question, "Do you think that breathing 
smoke from other people's cigarettes or from other tobacco products is...?", with the following response options: 'not at all harmful to one's health', 'somewhat harmful to one's health', and 'very harmful to one's health'. In this analysis, respondents who answered 'very harmful to one's health' were considered to perceive SHS as 'very harmful'.

\section{Current tobacco product use}

Tobacco product use was determined by respondents' answers to questions on use of six products (cigarettes, cigars/cigarillos/little cigars, water pipes, pipes, chew/ snuff/dip, and snus); respondents were classified into four categories: 1) combustible only use; 2) noncombustible only use; 3 ) combustible and noncombustible use; 4) and no tobacco use. 'Combustible only use' was defined as a respondent who reported smoking at least 100 cigarettes during their lifetime, and now smoked 'every day' or 'some days' and/or used cigars/cigarillos/little cigars, water pipes, or pipes on $\geq 1$ day during the past 30 days, but did not use a noncombustible product. 'Noncombustible only use' was defined as a respondent who reported using chewing tobacco/snuff/dip or snus on $\geq 1$ day during the past 30 days, but did not use a combustible product. 'Combustible and noncombustible use' was defined as a respondent who reported smoking at least 100 cigarettes during their lifetime and now smoked 'every day' or 'some days' and/or used cigars/cigarillos/little cigars, water pipes, pipes, chewing tobacco/ snuff/dip, or snus on $\geq 1$ day during the past 30 days. 'No tobacco use' was defined as a respondent who did not currently use combustible or noncombustible tobacco.

\section{Comprehensive smoke-free law coverage}

Comprehensive smoke-free law coverage was determined using the American Nonsmokers' Rights Foundation (ANRF) U.S. Tobacco Control Laws Database ${ }^{\odot}$, which tracks U.S. municipal, county, and state laws relating to tobacco [33]. Laws included in this database are identified through systematic scanning of tobacco control publications, Web sites and e-mail discussion lists, biannual solicitation of information from tobacco control professionals, and partnerships. Identified tobacco control laws are coded by senior staff members at ANRF; the online legal research database of state and/or local comprehensive smoke-free laws are regularly updated quarterly. For the purposes of this study, respondents were categorized according to the proportion of individuals in their state covered by a state and/or local comprehensive smoke-free law as of July 1, 2010 [33]. A comprehensive smoke-free law was defined as an ordinance or regulation that prohibits smoking in all indoor areas of non-hospitality workplaces, restaurants, and freestanding bars, including attached bars or separately ventilated rooms with no size exemptions. For the purposes of analysis, comprehensive smoke-free laws were categorized as follows: $100 \%$ (statewide law); 20-99 \%; 1-19\%; $0 \%$ (no local or statewide laws). These categories were selected based on the population distribution of coverage across states so as to ensure that statistically reliable comparisons could be made across categories.

\section{Sociodemographic characteristics}

Sociodemographic characteristics of respondents that were assessed included: sex (male or female); age group $(18-24,25-44,45-64$, or $\geq 65$ years); race/ethnicity (non-Hispanic white, non-Hispanic black, non-Hispanic Asian, non-Hispanic American Indian/Alaska native, non-Hispanic Native Hawaiian/Pacific Islander, nonHispanic multirace, non-Hispanic other, or Hispanic); educational attainment (0-12 years [no diploma], Graduate Equivalency Degree (GED), high school graduate, some college [no degree], associate degree, undergraduate degree, or graduate degree); marital status (single/separated/divorced/widowed or married/living with a partner); annual household income $(<\$ 20,000$, $\$ 20,000-\$ 49,999, \$ 50,000-\$ 99,999, \geq \$ 100,000$, or unspecified); U.S. Census region (Northeast, Midwest, South, or West); sexual orientation (heterosexual/ straight, lesbian/gay/bisexual/transgender [LGBT], or unspecified); and whether the respondent lived in a household with children $\leq 17$ years old (yes or no).

\section{Analyses}

Data were analyzed using SAS-Callable SUDAAN 10 (SAS Institute Inc., Research Triangle Park, NC) and weighted to adjust for the differential probabilities of selection and response [31]. The landline data were first weighted by the inverse of the probability of selection of the telephone number, a nonresponse adjustment, and adjustments for the number of landlines and the number of eligible subjects in the household. The cellular telephone data were first weighted by the inverse of the probability of selection of the telephone number and a nonresponse adjustment. Next, the data were poststratified by state according to the distribution of demographic variables (sex, age, race/ethnicity, marital status, and educational attainment) and telephone type. For states with a small number of cellular telephone respondents, the use of both landline and cellular telephone data resulted in a large unequal weighting effect and, therefore, large estimated variances of survey estimates and small effective sample sizes. As a result, the national and state estimates were calculated differently. For national estimates, we included both cellular telephone and landline respondents. For state estimates, cellular telephone respondents were included only for the 12 
states that had a cellular telephone sample of 200 or more respondents (California, Florida, Georgia, Illinois, Louisiana, New Jersey, New York, North Carolina, Ohio, Oklahoma, Pennsylvania, and Texas).

Descriptive analyses, including point estimates and $95 \%$ confidence intervals (CI), were calculated for each respondent characteristic-overall, by state, and by tobacco use status. Differences between estimates were considered statistically significant if $95 \%$ CIs did not overlap. Additionally, a binary logistic regression model was constructed with perceptions about SHS exposure being 'very harmful' as the dependent variable; independent variables included: sex, age group, race/ethnicity, educational attainment, marital status, annual household income, U.S. region, sexual orientation, whether respondents had children $\leq 17$ years old living in the household, comprehensive smoke-free law coverage, and current tobacco use. Separate logistic regression models were constructed to predict perceived harm from SHS exposure among each respective category of tobacco users (i.e., combustible only use, noncombustible only use, combustible and noncombustible use, no tobacco use), each of which adjusted for the same covariates as the overall model (excluding tobacco use).

\section{Results}

\section{Perception of harm from secondhand smoke exposure,} overall

Nationally, $64.5 \%$ of adults reported that SHS exposure was 'very harmful', $31.5 \%$ reported it was 'somewhat harmful', and $4.0 \%$ of reported it was 'not at all harmful' (Table 1). The unadjusted prevalence of perceiving that SHS exposure was 'very harmful' was higher among females (72.5 \%) compared to males (56.3\%); among respondents with an unspecified sexual orientation (79.2\%) compared to heterosexual/straight individuals (64.5\%) and LGBT individuals (59.5\%); and among respondents with children living in the household (68.2\%) compared to those without children living in the household $(62.0 \%) \quad(p<0.05)$. The prevalence of perceiving that SHS exposure was 'very harmful' was lower among residents of states in the Midwest (60.5\%) compared to those in other regions (South $=64.5 \%$; Northeast = $66.0 \%$; West $=67.5 \%)(p<0.05)$.

\section{Perception of harm from secondhand smoke exposure, by state}

Table 2 shows the prevalence of harm perceptions toward SHS among adults by state. The prevalence of those who perceived SHS exposure to be 'very harmful' to health ranged from $73.5 \%$ in Utah to $53.7 \%$ in Kentucky; the prevalence of those who considered exposure to be 'somewhat harmful' ranged from $39.5 \%$ in Kentucky to $25.3 \%$ in Florida; and the prevalence of those who considered exposure to be 'not at all harmful' ranged from $6.8 \%$ in Kentucky to $2.4 \%$ in Delaware.

\section{Adjusted odds of perceived harm, overall}

Overall, the adjusted odds of perceiving SHS to be 'very harmful' were higher among females (adjusted odds ratio $[\mathrm{AOR}]=1.6,95 \% \mathrm{CI}=1.4-1.7)$ compared to men; among non-Hispanic Blacks $(\mathrm{AOR}=2.0,95 \%$ $\mathrm{CI}=1.7-2.3)$, non-Hispanic Asians $(\mathrm{AOR}=1.7$, $95 \%$ $\mathrm{CI}=1.1-2.5)$, non-Hispanic American Indian/Alaska Natives $(\mathrm{AOR}=1.5,95 \% \mathrm{CI}=1.1-2.0)$, non-Hispanic others $(\mathrm{AOR}=2.1,95 \% \mathrm{CI}=1.2-3.8)$, and Hispanics $(\mathrm{AOR}=1.8,95 \% \mathrm{CI}=1.5-2.2)$ compared to nonHispanic whites; among respondents with children living in the household $(\mathrm{AOR}=1.3,95 \% \mathrm{CI}=1.1-1.4)$ compared to respondents without children living in the household; and respondents covered by a $100 \%$ smoke-free law $(\mathrm{AOR}=1.1,95 \% \mathrm{CI}=1.1-1.3)$ compared to those living in states with less coverage (Table 3).

The odds of perceiving SHS to be 'very harmful' were lower among respondents aged 45-64 (AOR = $0.8,95 \% \mathrm{CI}=0.7-0.9)$ compared to respondents $18-$ 24 years of age; those with an annual household incomes $>\$ 20,000$ compared to respondents with an annual income of $<\$ 20,000$; and those living in the Midwest $(\mathrm{AOR}=0.8,95 \% \mathrm{CI}=0.7-0.9)$ compared to those in the West.

\section{Adjusted odds of perceived harm, by tobacco use status} Perceptions that SHS was 'very harmful' were highest among those who did not use tobacco (76.5\%), followed by noncombustible only users (62.1\%), combustible only users (47.9\%), and combustible and noncombustible users (40.7\%) (Table 3). By tobacco use, the odds of perceiving SHS to be 'very harmful' were lower among noncombustible only users (AOR $=0.7, \quad 95 \% \mathrm{CI}=0.5-0.9)$, combustible only users (AOR $=0.3,95 \% \mathrm{CI}=0.2-0.4$ ), and combustible and noncombustible users $(\mathrm{AOR}=0.3,95 \% \mathrm{CI}=0.2-0.4)$ compared to those who did not use tobacco.

Among combustible only users, odds of perceiving SHS to be 'very harmful' were higher among females compared to males, non-Hispanic Blacks, nonHispanic American Indian/Alaska Natives compared to non-Hispanic whites, and among respondents with children $\leq 17$ years old living in the household compared to respondents without children living in the household; the odds were lower among respondents $\geq 45$ years of age compared to those 18-24 years of age, high school graduates, those with some college or an undergraduate or graduate degree compared to those with $0-12$ years of education, and respondents 
Table 1 Percentage of U.S. adults who think breathing smoke from other people's cigarettes or tobacco products causes harm, by selected characteristics-National Adult Tobacco Survey (NATS) 2009-2010

\begin{tabular}{|c|c|c|c|c|}
\hline & $\begin{array}{l}\text { Unweighted } \\
\text { frequency }\end{array}$ & $\begin{array}{l}\text { Not at all harmful } \\
\text { to one's health }\end{array}$ & Somewhat harmful & Very harmful \\
\hline Characteristics & $n$ & $\%(95 \% \mathrm{Cl})$ & $\%(95 \% \mathrm{Cl})$ & $\%(95 \% \mathrm{Cl})$ \\
\hline Overall & 97,805 & $4.0(3.7-4.3)$ & $31.5(30.9-32.1)$ & $64.5(63.9-65.2)$ \\
\hline \multicolumn{5}{|l|}{ Sex } \\
\hline Male & 38,659 & $5.3(4.8-5.7)$ & $38.4(37.4-39.4)$ & $56.3(55.3-57.4)$ \\
\hline Female & 59,146 & $2.8(2.5-3.1)$ & $24.8(24.1-25.5)$ & $72.5(71.7-73.2)$ \\
\hline \multicolumn{5}{|l|}{ Age (years) } \\
\hline $18-24$ & 4780 & $2.6(2.0-3.3)$ & $32.4(30.4-34.5)$ & $64.9(62.9-67.0)$ \\
\hline $25-44$ & 25,915 & $3.0(2.6-3.5)$ & $30.9(29.8-32.0)$ & $66.0(64.9-67.2)$ \\
\hline $45-64$ & 41,968 & $4.9(4.4-5.3)$ & $33.6(32.7-34.5)$ & $61.5(60.5-62.4)$ \\
\hline$\geq 65$ & 25,142 & $5.8(5.2-6.4)$ & $27.2(26.1-28.3)$ & $67.0(65.8-68.2)$ \\
\hline \multicolumn{5}{|l|}{ Race/ethnicity } \\
\hline White, non-Hispanic & 81,517 & $4.2(3.9-4.4)$ & $35.7(35.1-36.3)$ & $60.1(59.5-60.8)$ \\
\hline Black, non-Hispanic & 7244 & $3.0(2.3-3.6)$ & $21.5(19.7-23.3)$ & $75.5(73.7-77.4)$ \\
\hline Asian, non-Hispanic & 1645 & a & $21.0(15.6-26.5)$ & $75.9(70.3-81.5)$ \\
\hline Al/AN, non-Hispanic & 1495 & $7.5(4.9-10.0)$ & $28.4(23.5-33.3)$ & $64.1(58.9-69.3)$ \\
\hline NH/PI, non-Hispanic & 399 & a & $28.0(18.5-37.4)$ & $66.5(56.6-76.4)$ \\
\hline Non-Hispanic, multirace & 1220 & $3.7(2.1-5.4)$ & $28.4(23.5-33.2)$ & $67.9(62.8-73.0)$ \\
\hline Non-Hispanic, other & 481 & a & $23.0(15.4-30.5)$ & $69.8(61.2-78.3)$ \\
\hline Hispanic & 3804 & $3.8(2.7-4.8)$ & $20.9(18.5-23.3)$ & $75.3(72.8-77.9)$ \\
\hline \multicolumn{5}{|l|}{ Education } \\
\hline $0-12$ years (no diploma) & 6694 & $5.5(4.5-6.4)$ & $27.2(24.9-29.5)$ & $67.4(65.0-69.8)$ \\
\hline GED & 1696 & $6.1(3.9-8.4)$ & $33.8(29.7-37.8)$ & $60.1(55.9-64.4)$ \\
\hline High school graduate & 21,078 & $4.9(4.3-5.5)$ & $32.5(31.3-33.7)$ & $62.6(61.3-63.9)$ \\
\hline Some college (no degree) & 15,778 & $3.9(3.4-4.5)$ & $32.5(31.1-33.9)$ & $63.6(62.2-65.0)$ \\
\hline Associate degree & 14,241 & $3.4(2.8-3.9)$ & $31.1(29.7-32.5)$ & $65.5(64.1-67.0)$ \\
\hline Undergraduate degree & 23,148 & $2.3(2.0-2.6)$ & $33.2(32.0-34.3)$ & $64.6(63.4-65.7)$ \\
\hline Graduate degree & 15,170 & $2.2(1.8-2.7)$ & $30.8(29.5-32.2)$ & $66.9(65.6-68.3)$ \\
\hline \multicolumn{5}{|l|}{ Marital status } \\
\hline Married/partnered & 59,208 & $3.7(3.4-4.0)$ & $30.9(30.1-31.6)$ & $65.4(64.6-66.2)$ \\
\hline Single/separated/divorced or widowed & 38,597 & $4.4(4.0-4.8)$ & $32.3(31.3-33.3)$ & $63.3(62.2-64.3)$ \\
\hline \multicolumn{5}{|l|}{ Annual household income } \\
\hline$<\$ 20,000$ & 11,039 & $6.1(5.2-7.0)$ & $25.9(24.1-27.6)$ & $68.1(66.2-70.0)$ \\
\hline$\$ 20,000-\$ 49,999$ & 31,555 & $4.0(3.6-4.4)$ & $31.4(30.3-32.5)$ & $64.6(63.4-65.7)$ \\
\hline$\$ 50,000-\$ 99,999$ & 33,335 & $3.8(3.4-4.3)$ & $33.0(32.0-34.1)$ & $63.1(62.1-64.2)$ \\
\hline$\geq \$ 100,000$ & 18,357 & $3.0(2.4-3.6)$ & $34.2(32.9-35.5)$ & $62.8(61.4-64.2)$ \\
\hline Unspecified & 3519 & $3.1(2.1-4.0)$ & $27.8(24.7-30.9)$ & $69.1(65.9-72.3)$ \\
\hline \multicolumn{5}{|l|}{ U.S. region } \\
\hline Northeast & 17,685 & $3.3(2.8-3.8)$ & $30.7(29.5-32.0)$ & $66.0(64.7-67.3)$ \\
\hline Midwest & 20,255 & $4.4(3.9-4.9)$ & $35.1(34.0-36.2)$ & $60.5(59.4-61.7)$ \\
\hline South & 38,595 & $4.3(3.9-4.8)$ & $31.3(30.3-32.3)$ & $64.4(63.3-65.4)$ \\
\hline West & 21,270 & $3.7(3.1-4.3)$ & $28.8(27.2-30.3)$ & $67.5(65.9-69.1)$ \\
\hline
\end{tabular}


Table 1 Percentage of U.S. adults who think breathing smoke from other people's cigarettes or tobacco products causes harm, by selected characteristics-National Adult Tobacco Survey (NATS) 2009-2010 (Continued)

\begin{tabular}{|c|c|c|c|c|}
\hline \multicolumn{5}{|l|}{ Sexual orientation } \\
\hline Heterosexual/straight & 94,698 & $4.0(3.7-4.2)$ & $31.5(30.9-32.2)$ & $64.5(63.8-65.1)$ \\
\hline LGBT & 2180 & $3.6(2.3-4.8)$ & 36.9 (32.6-41.2) & $59.5(55.2-63.9)$ \\
\hline Unspecified & 927 & $6.9(3.4-10.3)$ & $13.9(9.6-18.3)$ & $79.2(73.8-84.6)$ \\
\hline \multicolumn{5}{|c|}{ Children $\leq 17$ years old living in household } \\
\hline Yes & 30,626 & $3.0(2.6-3.5)$ & $28.8(27.7-29.8)$ & $68.2(67.1-69.3)$ \\
\hline No & 67,179 & $4.7(4.4-5.0)$ & $33.4(32.6-34.1)$ & $62.0(61.2-62.7)$ \\
\hline \multicolumn{5}{|l|}{ Tobacco use ${ }^{c}$} \\
\hline Combustible only & 13,665 & $8.7(7.8-9.6)$ & $43.5(41.8-45.1)$ & $47.9(46.2-49.5)$ \\
\hline Noncombustible only & 527 & $5.2(2.4-8.0)$ & $32.6(25.3-40.0)$ & $62.1(54.6-69.7)$ \\
\hline Combustible \& Noncombustible & 1080 & $9.2(6.5-12.0)$ & $50.1(44.8-55.4)$ & $40.7(35.5-46.0)$ \\
\hline No tobacco use & 49,778 & $2.0(1.7-2.2)$ & $21.5(20.7-22.4)$ & $76.5(75.6-77.3)$ \\
\hline \multicolumn{5}{|c|}{ Population coverage of smoke-free laws ${ }^{b}$} \\
\hline $100 \%$ state laws & 46,285 & $4.0(3.6-4.4)$ & $31.1(30.3-31.9)$ & $64.9(64.1-65.8)$ \\
\hline 20-99 \% state laws & 15,902 & $4.3(3.6-4.9)$ & $33.6(31.8-35.4)$ & $62.1(60.3-64.0)$ \\
\hline $1-19 \%$ state laws & 16,333 & $3.7(3.1-4.3)$ & $29.1(27.5-30.7)$ & $67.2(65.5-68.9)$ \\
\hline $0 \%$ state or local laws & 17,785 & $4.2(3.7-4.7)$ & $33.8(32.6-35.0)$ & $62.0(60.8-63.2)$ \\
\hline \multicolumn{5}{|c|}{$\begin{array}{l}\text { Note: Bold values indicate statistical significance }(p<0.05) \text { when compared to all other categories for the respective characteristic } \\
\text { Abbreviations: Al/AN American Indian/Alaska Native, NH/PI Native Hawaiian/Pacific Islander, GED Graduate Equivalency Degree, LGBT Lesbian, Gay, Bisexual, } \\
\text { or Transgender } \\
\text { aEstimate excluded due to relative standard error }>30 \% \\
\text { bPopulation coverage of smoke-free laws was based on the American Nonsmokers' Rights Foundation U.S. Tobacco Control Laws Database } \\
\text { cent of the population covered by state and/or local compresensive smoke-free laws as of July } 1,2010 \\
\text { 'Combustible only use is defined as those who currently smoke cigarettes, pipes, hookah, or cigars and do not use snus or chew/snuff/dip. Noncombustible only } \\
\text { use is defined as those who use snus or chew/snuff/dip and do not currently smoke cigarettes, pipes, hookah or cigars. Combustible and noncombustible users } \\
\text { are those who use both combustible and noncombustible tobacco products }\end{array}$} \\
\hline
\end{tabular}

with an annual household income of $\$ 50,000-\$ 99,000$ compared to those with a household income $<\$ 20,000$.

Among noncombustible only users, the odds were higher among respondents with children $\leq 17$ years old living in the household compared to respondents without children living in the household and those living in a state with $100 \%$ or $20-99 \%$ population coverage of state and/or local smoke-free laws compared to those living in states with less coverage; the odds were lower among respondents with an associates and graduate degree compared to those with $0-$ 12 years of education, respondents with an income of $\$ 50,000-\$ 99,000$ compared to those with a household income $<\$ 20,000$.

Among combustible and noncombustible users, the odds were lower among respondents residing in locations with $100 \%$ smoke-free laws compared to those without any $100 \%$ state/local smoke-free law coverage. Among those who did not use tobacco, the odds were higher among females, non-Hispanic Blacks, non-Hispanic Asians and Hispanics, respondents with children $\leq 17$ years old living in the household, and those covered by $100 \%$ smoke-free laws; the odds were lower among respondents with an annual household income of $\geq \$ 20,000$ and those in the Midwest.

\section{Discussion}

The findings from this study reveal that $96 \%$ of U.S. adults perceive SHS exposure as harmful, with nearly two-thirds $(64.5 \%)$ perceiving it to be 'very harmful'. The prevalence of perceiving that SHS exposure was 'very harmful' was significantly higher among females, racial/ethnic minorities, respondents with children $\leq 17$ years old living in the household, and those covered by $100 \%$ smoke-free laws. Population-level perception of SHS harm data can be an important component in understanding societal contexts for developing educational campaigns [27]. Such efforts could include public health educational initiatives and media campaigns, such as CDC's "Tips from Former Smokers," which included ads related to the adverse health effects of SHS exposure [34].

The present study expands upon a previous study that examined perceptions of harm from SHS exposure among youth [8]. However, in this study, we assessed the proportion of adults who perceived that SHS exposure 
Table 2 Percentage of U.S. adults who think breathing smoke from other people's cigarettes or other tobacco products causes harm, by state-National Adult Tobacco Survey (NATS) 2009-2010

\begin{tabular}{|c|c|c|c|c|}
\hline \multirow[t]{2}{*}{ State } & $\begin{array}{l}\text { Unweighted } \\
\text { frequency }\end{array}$ & $\begin{array}{l}\text { Not at all harmful } \\
\text { to one's health }\end{array}$ & Somewhat harmful & Very harmful \\
\hline & $n$ & $\%(95 \% \mathrm{Cl})$ & $\%(95 \% \mathrm{Cl})$ & $\%(95 \% \mathrm{Cl})$ \\
\hline \multicolumn{5}{|c|}{$100 \%$ of population covered by a comprehensive smoke-free law ${ }^{a}$} \\
\hline Arizona & 1539 & $5.7(3.7-7.7)$ & $28.2(24.2-32.1)$ & $66.1(61.9-70.4)$ \\
\hline Colorado & 1634 & $3.4(2.2-4.5)$ & $35.7(32.0-39.5)$ & $60.9(57.1-64.7)$ \\
\hline Delaware & 1585 & $2.4(1.3-3.4)$ & $32.0(25.2-38.7)$ & $65.6(59.0-72.3)$ \\
\hline District of Columbia & 1427 & b & $30.0(22.1-38.0)$ & $67.1(59.1-75.1)$ \\
\hline Florida ${ }^{c}$ & 1859 & $5.6(3.8-7.5)$ & $25.3(22.7-27.9)$ & $69.1(66.2-71.9)$ \\
\hline Hawaii & 1509 & $4.2(2.0-6.4)$ & $29.5(24.3-34.8)$ & $66.3(60.8-71.7)$ \\
\hline |llinois $^{c}$ & 1698 & $4.0(2.8-5.2)$ & $33.3(30.2-36.4)$ & $62.7(59.6-65.9)$ \\
\hline lowa & 1768 & $2.7(1.8-3.7)$ & $36.0(31.8-40.3)$ & $61.2(57.0-65.5)$ \\
\hline Louisiana $^{c}$ & 5164 & $4.7(3.8-5.6)$ & $27.3(25.3-29.4)$ & $67.9(65.8-70.0)$ \\
\hline Maine & 1723 & $3.7(2.3-5.2)$ & $31.4(26.6-36.2)$ & $64.9(60.0-69.7)$ \\
\hline Maryland & 1548 & $2.4(1.3-3.5)$ & $34.3(30.7-37.9)$ & $63.3(59.7-67.0)$ \\
\hline Massachusetts $^{c}$ & 1563 & $3.7(2.3-5.2)$ & $33.1(29.7-36.4)$ & $63.2(59.8-66.6)$ \\
\hline Minnesota & 1563 & $5.2(2.9-7.4)$ & $38.4(34.8-41.9)$ & $56.4(52.8-60.1)$ \\
\hline Montana & 1579 & $5.2(2.7-7.7)$ & $31.7(27.3-36.1)$ & $63.1(58.5-67.8)$ \\
\hline Nebraska & 1587 & $5.2(2.3-8.0)$ & $37.4(31.4-43.4)$ & $57.4(51.4-63.4)$ \\
\hline Nevada & 1554 & $5.4(3.3-7.5)$ & $34.8(29.7-40.0)$ & $59.8(54.6-65.0)$ \\
\hline New Jersey ${ }^{c}$ & 3308 & $3.4(2.4-4.4)$ & $32.1(29.8-34.4)$ & $64.5(62.1-66.8)$ \\
\hline New Mexico & 1488 & $3.9(1.8-6.0)$ & $27.6(22.8-32.4)$ & $68.5(63.6-73.5)$ \\
\hline New York ${ }^{c}$ & 1839 & $2.5(1.6-3.4)$ & $27.1(24.4-29.8)$ & 70.4 (67.6-73.2) \\
\hline Ohio $^{c}$ & 1811 & $4.7(3.4-6.0)$ & $35.3(32.6-38.1)$ & $59.9(57.1-62.7)$ \\
\hline Oregon & 1697 & $3.4(1.8-5.0)$ & $33.9(30.5-37.3)$ & $62.7(59.1-66.2)$ \\
\hline Rhode Island & 1566 & b & $30.1(26.0-34.2)$ & $65.4(61.0-69.8)$ \\
\hline Utah & 1796 & $2.6(1.5-3.7)$ & $23.9(20.5-27.4)$ & 73.5 (69.9-77.0) \\
\hline Vermont & 1734 & $2.0(1.1-3.0)$ & $32.0(26.3-37.8)$ & $65.9(60.1-71.7)$ \\
\hline \multicolumn{5}{|c|}{ 20-99 \% of population covered by comprehensive smoke-free law } \\
\hline Washington & 1746 & $3.3(1.9-4.8)$ & $33.3(30.4-36.3)$ & $63.3(60.2-66.4)$ \\
\hline Alaska & 1566 & $2.6(1.4-3.8)$ & $28.5(21.6-35.5)$ & $68.9(61.8-75.9)$ \\
\hline Indiana & 1701 & $4.8(3.3-6.4)$ & $35.0(31.8-38.2)$ & $60.2(56.9-63.4)$ \\
\hline Kansas & 1602 & $4.6(2.3-7.0)$ & $35.2(30.6-39.8)$ & $60.2(55.4-64.9)$ \\
\hline Kentucky & 1532 & $6.8(4.3-9.2)$ & $39.5(34.6-44.5)$ & $53.7(48.7-58.7)$ \\
\hline North Dakota & 1850 & b & $30.5(21.1-39.9)$ & $65.6(56.2-75.1)$ \\
\hline South Carolina & 4165 & $4.2(2.6-5.9)$ & $31.8(28.1-35.5)$ & $63.9(60.1-67.7)$ \\
\hline Texas $^{c}$ & 1942 & $3.6(2.7-4.6)$ & $32.7(29.6-35.7)$ & $63.7(60.6-66.8)$ \\
\hline West Virginia & 1544 & $4.6(2.7-6.5)$ & $30.3(26.2-34.3)$ & $65.1(60.9-69.4)$ \\
\hline \multicolumn{5}{|c|}{ 1-19\% of population covered by a comprehensive smoke-free laws } \\
\hline Alabama & 1611 & $3.7(2.3-5.2)$ & $29.4(25.5-33.3)$ & $66.8(62.7-70.9)$ \\
\hline Arkansas & 2384 & b & $35.0(27.6-42.4)$ & $56.9(49.5-64.4)$ \\
\hline California $^{c}$ & 2159 & $3.4(2.3-4.4)$ & $26.1(23.4-28.8)$ & $70.5(67.7-73.4)$ \\
\hline Georgia $^{c}$ & 3976 & $3.4(2.5-4.2)$ & $29.0(26.6-31.5)$ & $67.6(65.0-70.1)$ \\
\hline Mississippi & 1466 & $3.0(1.9-4.1)$ & $27.0(21.3-32.6)$ & $70.1(64.3-75.8)$ \\
\hline
\end{tabular}


Table 2 Percentage of U.S. adults who think breathing smoke from other people's cigarettes or other tobacco products causes harm, by state-National Adult Tobacco Survey (NATS) 2009-2010 (Continued)

\begin{tabular}{lllll}
\hline Missouri & 1666 & $3.8(2.6-5.0)$ & $38.2(34.9-41.4)$ & $58.0(54.7-61.4)$ \\
Wisconsin & 1619 & $4.3(2.5-6.0)$ & $35.4(31.8-39.0)$ & $60.4(56.7-64.1)$ \\
Wyoming & 1452 & $\mathrm{~b}$ & $37.4(30.0-44.8)$ & $58.2(50.9-65.5)$ \\
$\begin{array}{l}\text { \% of population covered by comprehensive smoke-free law } \\
\text { Connecticut }\end{array}$ & & & \\
Idaho & 1500 & $3.1(1.9-4.3)$ & $30.3(26.6-34.0)$ & $66.6(62.8-70.3)$ \\
Michigan & 1551 & $3.3(1.5-5.0)$ & $31.5(25.7-37.3)$ & $65.2(59.3-71.1)$ \\
New Hampshire & 1656 & $4.6(3.1-6.2)$ & $33.4(30.1-36.8)$ & $61.9(58.5-65.4)$ \\
North Carolina ${ }^{c}$ & 1638 & $\mathrm{~b}$ & $32.0(27.8-36.3)$ & $64.2(59.7-68.7)$ \\
Oklahoma & 1665 & $4.8(3.3-6.2)$ & $36.5(33.2-39.8)$ & $58.7(55.4-62.1)$ \\
Pennsylvania & 3098 & $3.8(3.0-4.7)$ & $30.7(28.7-32.8)$ & $65.4(63.3-67.5)$ \\
South Dakota & 2814 & $4.1(3.1-5.1)$ & $33.9(31.6-36.2)$ & $62.0(59.7-64.3)$ \\
Tennessee & 1734 & $3.1(2.0-4.2)$ & $30.4(26.4-34.5)$ & $66.4(62.3-70.5)$ \\
Virginia & 1617 & $4.6(3.2-6.0)$ & $33.4(29.7-37.0)$ & $62.0(58.3-65.8)$ \\
National & 2012 & $3.6(2.5-4.7)$ & $33.7(30.8-36.6)$ & $62.7(59.8-65.7)$ \\
\hline
\end{tabular}

${ }^{a}$ Population coverage of smoke-free laws was based on the American Nonsmokers' Rights Foundation U.S. Tobacco Control Laws Database ${ }^{\odot}$ and represent the percent of the population covered by state and/or local comprehensive smoke-free laws as of July 1, 2010

${ }^{\mathrm{b}}$ Relative SE $>30 \%$

${ }^{c}$ Estimates calculated among both landline and cellular telephone respondents. All other state estimates were calculated among landline respondents only

was 'very harmful'. The rationale for assessing high levels of perceptions toward SHS was based on the findings of the 2006 Surgeon General's report, which concluded that there is no safe level of exposure to SHS and that the only way to fully protect the public from SHS exposure is to completely eliminate smoking in indoor public places and worksites [1]. This is the first study to examine perceptions of harm by subgroupings of tobacco use status. The findings reveal that nearly two-thirds of noncombustible only tobacco users perceived SHS as 'very harmful' compared to approximately half of combustible only users and two-fifths of dual users of both combustible and noncombustible tobacco. The lower levels of perceptions among dual users may be attributable to multiple factors, including greater levels of tobacco dependence among these individuals [9], lower levels of understanding of the health hazards of tobacco use [11], and increased receptivity to protobacco messaging. These findings underscore the importance of continued efforts to educate all tobacco users about the benefits of smoke-free environments as part of a comprehensive approach to reduce tobacco use and SHS exposure, particularly among combustible tobacco users and dual users of both combustible and noncombustible tobacco. These findings also underscore the importance of educating smokers on the importance of quitting smoking completely as no level of exposure to SHS is risk-free.

Variations in perceptions about the harms of SHS were also observed by sociodemographic groups. More specifically, the perception that SHS was 'very harmful' was higher in females, non-Hispanic racial/ethnic minorities and Hispanics, and respondents with children $\leq 17$ years' old living in the household. These findings are generally consistent with those from other studies [8, 35-37]. Of note, estimates of harm perceptions by age differed by current smoking status. For example, among combustible only users, the odds of perceiving SHS to be 'very harmful' were lower for those $\geq 45$ years of age compared to respondents $18-24$ years of age. These variations in perceptions by age could be due, in part, to varying tobacco use rates among age groups [8] or factors related to the social disapproval of tobacco use $[9,38]$. Consistent with past studies, respondents who reported living with children in the household had higher odds of perceiving that SHS was harmful [2], suggesting greater receptivity toward tobacco-related health messages and understanding of the dangers of SHS among individuals with children. A study by Tan and colleagues [7] suggested that raising public awareness to information about the harmfulness of SHS influenced public perceptions. More research into the influence of public education campaigns on the health effects of SHS could further increase awareness of the harms of SHS.

Variations in perceptions about the harm of SHS were also observed across states. For example, Kentucky had the lowest prevalence of adults who believed that SHS was 'very harmful', while Utah, California, and New York had the highest. The higher prevalence in these states may be attributable to lower smoking rates and/or longstanding comprehensive tobacco control programs in 
Table 3 Percent and adjusted odds ratios of U.S. adults who think breathing smoke from other people's cigarettes or other tobacco products was 'very harmful' overall by tobacco use status ${ }^{a}$ and selected characteristics-National Adult Tobacco Survey (NATS) 2009-2010

\begin{tabular}{|c|c|c|c|c|c|c|c|c|c|c|}
\hline \multirow[b]{2}{*}{ Characteristics } & \multicolumn{2}{|c|}{$\begin{array}{l}\text { Combustible only } \\
(n=5648)\end{array}$} & \multicolumn{2}{|c|}{$\begin{array}{l}\text { Noncombustible only } \\
(n=297)\end{array}$} & \multicolumn{2}{|l|}{$\begin{array}{l}\text { Combustible \& } \\
\text { Noncombustible } \\
(n=441)\end{array}$} & \multicolumn{2}{|l|}{$\begin{array}{l}\text { No tobacco use } \\
(n=38,074)\end{array}$} & \multicolumn{2}{|l|}{$\begin{array}{l}\text { Overall } \\
(n=44,460)\end{array}$} \\
\hline & $\overline{\%}$ & $\begin{array}{l}\text { AOR } \\
(95 \% \mathrm{Cl})^{\mathrm{b}}\end{array}$ & $\overline{\%}$ & $\begin{array}{l}\text { AOR } \\
(95 \% \mathrm{Cl})^{\mathrm{b}}\end{array}$ & $\overline{\%}$ & $\begin{array}{l}\text { AOR } \\
(95 \% \mathrm{Cl})^{\mathrm{b}}\end{array}$ & $\overline{\%}$ & $\begin{array}{l}\text { AOR } \\
(95 \% \mathrm{Cl})^{\mathrm{b}}\end{array}$ & $\overline{\%}$ & $\begin{array}{l}\text { AOR } \\
(95 \% \mathrm{Cl})^{\mathrm{b}}\end{array}$ \\
\hline Overall & $47.9(46.2-49.5)$ & $0.3(0.2-0.4)$ & $62.1(54.3-69.4)$ & $0.7(0.5-0.9)$ & $40.7(35.6-46.0)$ & $0.3(0.2-0.4)$ & $76.5(75.6-77.3)$ & 1.00 & $67.3(66.5-68.0)$ & e \\
\hline \multicolumn{11}{|l|}{ Sex } \\
\hline Male & $45.1(42.6-47.7)$ & 1.00 & $59.6(51.0-67.6)$ & 1.00 & $40.6(35.1-46.2)$ & 1.00 & $70.3(68.4-72.2)$ & 1.00 & $58.7(57.2-60.2)$ & 1.00 \\
\hline Female & $50.8(48.7-52.9)$ & $1.3(1.1-0.5)$ & $77.3(61.5-87.9)$ & $1.6(0.6-4.0)$ & $42.1(27.4-58.4)$ & $1.0(0.5-2.1)$ & $79.2(78.4-80.1)$ & $1.7(1.5-1.9)$ & $72.8(72.0-73.6)$ & $1.6(1.4-1.7)$ \\
\hline \multicolumn{11}{|l|}{ Age (years) } \\
\hline $18-24$ & $55.2(50.5-59.8)$ & 1.00 & $70.5(49.5-85.4)$ & 1.00 & $44.3(34.6-54.4)$ & 1.00 & $74.5(71.6-77.1)$ & 1.00 & $66.3(63.9-68.7)$ & 1.00 \\
\hline $25-44$ & $53.8(51.0-56.5)$ & $0.9(0.7-1.2)$ & $59.3(47.2-70.4)$ & $0.4(0.2-1.2)$ & $37.9(31.0-45.2)$ & $0.6(0.4-1.0)$ & 78.0 (76.4-79.6) & $1.0(0.8-1.3)$ & $68.8(67.4-70.2)$ & $1.0(0.8-1.1)$ \\
\hline $45-64$ & $39.8(37.5-42.1)$ & $0.6(0.5-0.8)$ & $59.9(48.1-70.6)$ & $0.6(0.2-1.6)$ & $39.0(28.7-50.4)$ & $0.7(0.4-1.3)$ & $75.8(74.6-77.0)$ & $1.0(0.9-1.2)$ & $64.6(63.4-65.7)$ & $0.8(0.7-0.9)$ \\
\hline$\geq 65$ & $33.8(29.7-38.3)$ & $0.5(0.4-0.6)$ & $65.1(45.4-80.8)$ & $0.4(0.1-1.6)$ & $55.9(34.9-74.9)$ & $1.7(0.7-4.3)$ & $76.0(74.6-77.4)$ & $1.1(0.0-1.4)$ & $70.0(68.5-71.4)$ & $0.9(0.8-1.1)$ \\
\hline \multicolumn{11}{|l|}{ Race/ethnicity } \\
\hline White, non-Hispanic & $41.8(40.0-43.5)$ & 1.00 & $59.6(51.2-67.6)$ & 1.00 & $35.2(30.1-40.8)$ & 1.00 & $73.0(72.1-73.8)$ & 1.00 & $62.6(61.8-63.4)$ & 1.00 \\
\hline Black, non-Hispanic & $60.4(56.0-64.7)$ & $2.1(1.7-2.6)$ & $64.1(37.1-84.4)$ & $1.1(0.4-3.2)$ & $69.4(45.4-86.1)$ & $6.3(2.2-8.1)$ & $83.1(80.8-85.3)$ & $1.9(1.6-2.3)$ & $76.3(74.2-78.3)$ & $2.0(1.7-2.3)$ \\
\hline Asian, non-Hispanic & $48.0(33.4-63.0)$ & $1.2(0.6-2.3)$ & e & e & $12.6(1.3-61.4)$ & $0.2(0.0-3.4)$ & $82.7(73.8-89.1)$ & $1.8(1.1-3.0)$ & $78.3(70.7-84.3)$ & $1.7(1.1-2.5)$ \\
\hline Al/AN, non-Hispanic & $53.9(43.4-64.0)$ & $1.6(1.1-2.4)$ & $d$ & $0.2(0.0-2.1)$ & d & $1.33(0.6-3.1)$ & $81.1(71.0-88.3)$ & $1.6(0.9-2.7)$ & $65.0(58.4-71.0)$ & $1.5(1.1-2.0)$ \\
\hline $\mathrm{NH} / \mathrm{PI}$, non-Hispanic & $58.2(39.6-74.8)$ & $1.7(0.7-3.9)$ & e & e & $65.1(17.3-94.3)$ & $2.9(0.4-21.0)$ & $76.2(59.7-87.4)$ & $1.1(0.5-2.5)$ & $70.4(58.5-80.0)$ & $1.4(0.8-2.5)$ \\
\hline Non-Hispanic, multirace & $47.5(36.4-58.8)$ & $1.1(0.7-1.7)$ & $d$ & $0.6(0.1-3.5)$ & d & $2.9(0.7-11.9)$ & $80.4(73.2-86.0)$ & $1.5(1.0-2.3)$ & $66.5(60.2-72.3)$ & $1.3(1.0-1.7)$ \\
\hline Non-Hispanic, other & $57.9(36.7-76.6)$ & $1.7(0.7-4.1)$ & 96.5 (75.5-99.6) & $50.9(5.0-514.6)$ & $78.5(35.3-96.1)$ & $8.2(0.3-202.5)$ & $86.7(72.8-94.1)$ & $2.3(1.0-5.6)$ & $74.8(63.6-83.5)$ & $2.1(1.2-3.8)$ \\
\hline Hispanic & $63.8(56.8-70.3)$ & $1.9(1.4-2.7)$ & $86.3(45.4-98.0)$ & $7.8(0.6-109.8)$ & $96.7(85.7-99.3)$ & $3.3(1.4-7.8)$ & $82.7(79.5-85.5)$ & $1.8(1.4-2.2)$ & $77.3(74.3-80.1)$ & $1.8(1.5-2.2)$ \\
\hline \multicolumn{11}{|l|}{ Education } \\
\hline 0-12 years (no diploma) & $56.5(51.9-61.0)$ & 1.00 & $73.5(59.0-84.2)$ & 1.00 & $45.3(32.7-58.5)$ & 1.00 & $77.9(74.5-81.0)$ & 1.00 & $68.8(66.1-71.4)$ & 1.00 \\
\hline GED & $50.4(42.7-58.0)$ & $0.8(0.6-1.2)$ & $d$ & $0.6(0.1-3.8)$ & $49.3(28.8-70.0)$ & $1.8(0.7-4.6)$ & $73.7(65.9-80.2)$ & $0.8(0.6-1.2)$ & $59.2(53.8-64.4)$ & $0.9(0.7-1.2)$ \\
\hline High school graduate & $44.7(41.8-47.6)$ & $0.7(0.6-0.9)$ & $68.3(54.4-79.6)$ & $0.7(0.3-2.0)$ & $36.9(29.1-45.3)$ & $0.9(0.5-1.7)$ & $75.3(73.5-77.0)$ & $1.0(0.8-1.3)$ & $64.7(63.2-66.2)$ & $0.9(0.8-1.0)$ \\
\hline Some college (no degree) & $45.3(41.8-48.9)$ & $0.7(0.6-0.9)$ & $48.3(28.3-68.8)$ & $0.4(0.1-1.2)$ & $41.9(30.8-53.8)$ & $1.1(0.5-2.3)$ & $75.7(73.8-77.5)$ & $1.0(0.8-1.3)$ & $66.0(64.3-67.7)$ & $0.9(0.74-1.0)$ \\
\hline Associate degree & $49.3(45.4-53.3)$ & $0.9(0.7-1.1)$ & $39.7(22.3-60.3)$ & $0.1(0.0-0.5)$ & $34.4(23.9-46.8)$ & $1.0(0.5-2.2)$ & $79.1(77.4-80.7)$ & $1.3(1.0-1.6)$ & $69.5(67.8-71.2)$ & $1.0(0.9-1.2)$ \\
\hline Undergraduate degree & $41.0(37.2-44.8)$ & $0.7(0.5-0.9)$ & $58.6(36.8-77.5)$ & $0.5(0.1-1.8)$ & $40.7(26.3-57.0)$ & $1.4(0.6-3.6)$ & $75.7(74.2-77.1)$ & $1.1(0.9-1.4)$ & $68.9(67.5-70.3)$ & $0.9(0.8-1.1)$ \\
\hline Graduate degree & $40.4(34.7-46.4)$ & $0.7(0.5-0.9)$ & d & $0.1(0.0-0.7)$ & d & $1.0(0.3-3.3)$ & $76.6(75.0-78.2)$ & $1.1(0.9-1.4)$ & $71.6(69.9-73.2)$ & $1.0(0.8-1.1)$ \\
\hline \multicolumn{11}{|l|}{ Marital status } \\
\hline Married/partnered & $48.4(46.1-50.7)$ & $1.1(1.0-1.3)$ & $95.4(89.7-98.0)$ & $2.0(0.9-4.1)$ & $41.2(34.0-48.9)$ & $1.0(0.6-1.5)$ & 76.7 (75.7-77.8) & $1.1(1.0-1.2)$ & $68.6(67.6-69.6)$ & $1.1(1.1-1.2)$ \\
\hline
\end{tabular}


Table 3 Percent and adjusted odds ratios of U.S. adults who think breathing smoke from other people's cigarettes or other tobacco products was 'very harmful' overall by tobacco use status ${ }^{a}$ and selected characteristics-National Adult Tobacco Survey (NATS) 2009-2010 (Continued)

\begin{tabular}{|c|c|c|c|c|c|c|c|c|c|c|}
\hline $\begin{array}{l}\text { Single/separated/ divorced or } \\
\text { widowed }\end{array}$ & $47.4(45.0-49.7)$ & 1.00 & $94.0(88.5-97.0)$ & 1.00 & $40.3(33.2-47.7)$ & 1.00 & $76.1(74.7-77.5)$ & 1.00 & $65.6(64.4-66.8)$ & 1.00 \\
\hline \multicolumn{11}{|l|}{ Annual household income } \\
\hline$<\$ 20,000$ & $53.7(49.8-57.4)$ & 1.00 & $63.7(54.5-71.9)$ & 1.00 & $40.3(27.2-55.0)$ & 1.00 & $81.2(78.8-83.4)$ & 1.00 & $69.2(67.0-71.3)$ & 1.00 \\
\hline$\$ 20,000-\$ 49,999$ & $47.9(45.3-50.6)$ & $0.8(0.7-1.0)$ & $60.1(46.7-72.2)$ & $0.5(0.2-1.5)$ & $37.4(29.6-45.8)$ & $1.0(0.5-1.9)$ & $76.4(74.7-78.0)$ & $0.8(0.7-0.9)$ & $66.2(64.8-67.6)$ & $0.8(0.7-0.9)$ \\
\hline$\$ 50,000-\$ 99,999$ & $42.3(39.2-45.5)$ & $0.7(0.6-0.9)$ & $62.1(54.3-69.4)$ & $0.3(0.1-0.9)$ & $47.7(38.0-57.5)$ & $1.8(0.9-3.8)$ & $75.7(74.4-77.0)$ & $0.8(0.7-0.9)$ & $66.865 .5-68.1)$ & $0.8(0.7-0.9)$ \\
\hline$\geq \$ 100,000$ & $44.5(39.3-49.8)$ & $0.8(0.6-1.1)$ & $77.5(59.8-88.8)$ & $0.3(0.1-1.2)$ & $30.9(19.6-45.0)$ & $0.7(0.3-1.6)$ & $74.8(73.0-76.5)$ & $0.8(0.6-0.9)$ & $67.4(65.5-69.2)$ & $0.9(0.7-0.9)$ \\
\hline Unspecified & $58.2(50.1-66.0)$ & $1.1(0.8-1.6)$ & d & $0.2(0.0-0.8)$ & $60.6(39.2-78.6)$ & $2.6(0.9-7.3)$ & $75.3(71.2-79.0)$ & $0.8(0.6-1.0)$ & $70.8(67.1-74.2)$ & $0.9(0.7-1.1)$ \\
\hline \multicolumn{11}{|l|}{ U.S. region indicator } \\
\hline Northeast & $49.2(45.7-52.8)$ & $1.1(0.9-1.4)$ & $68.6(46.8-84.4)$ & $3.2(0.8-12.9)$ & $45.1(31.6-59.4)$ & $1.0(0.4-2.3)$ & $76.2(74.6-77.8)$ & $0.9(0.8-1.1)$ & $68.4(66.9-70.0)$ & $1.0(0.9-1.1)$ \\
\hline Midwest & $43.640 .4-46.8)$ & $0.8(0.7-1.0)$ & $56.1(40.6-70.6)$ & $1.1(0.4-3.2)$ & $32.6(23.3-43.5)$ & $0.6(0.3-1.2)$ & $73.3(71.8-74.8)$ & $0.8(0.7-0.9)$ & $63.1(61.6-64.5)$ & $0.8(0.7-0.9)$ \\
\hline South & $48.445 .8-50.9)$ & $1.0(0.8-1.2)$ & $64.8(53.6-74.5)$ & $2.2(0.8-6.2)$ & $42.0(34.6-49.7)$ & $0.7(0.4-1.3)$ & $76.9(75.5-78.2)$ & $1.0(0.8-1.1)$ & $67.2(65.9-68.4)$ & $1.0(0.8-1.1)$ \\
\hline West & $50.546 .0-54.9)$ & 1.00 & $59.5(39.5-76.7)$ & 1.00 & $45.0(32.7-58.1)$ & 1.00 & $78.9(76.7-81.0)$ & 1.00 & $70.5(68.5-72.5)$ & 1.00 \\
\hline \multicolumn{11}{|l|}{ Sexual orientation } \\
\hline Heterosexual/straight & $47.746 .0-49.4)$ & 1.00 & $62.0(54.1-69.4)$ & 1.00 & $41.3(36.2-46.7)$ & 1.00 & $76.4(75.5-77.2)$ & 1.00 & $67.2(66.5-68.0)$ & 1.00 \\
\hline LGBT & $47.3(39.1-55.7)$ & $0.9(0.6-1.2)$ & $80.4(4.5-97.0)$ & $1.5(0.1-21.1)$ & $d$ & $0.2(0.0-1.1)$ & 74.6 67.5-80.5) & $1.0(0.7-1.4)$ & $60.7(55.2-66.0)$ & $0.9(0.7-1.1)$ \\
\hline Unspecified & $63.7(41.4-81.3)$ & $1.5(0.6-3.9)$ & d & $0.0(0.0-0.5)$ & $81.9(41.8-96.6)$ & $8.1(1.2-56.3)$ & $83.3(76.8-88.3)$ & $1.3(0.8-2.0)$ & $80.2(73.5-85.5)$ & $1.3(0.9-1.9)$ \\
\hline \multicolumn{11}{|c|}{ Children $\leq 17$ years old living in household } \\
\hline Yes & $56.7(53.9-59.4)$ & $1.4(1.2-1.6)$ & $66.1(54.9-75.8)$ & $2.0(1.1-4.0)$ & $42.8(35.0-51.0)$ & $1.4(0.9-2.3)$ & $79.1(77.7-80.4)$ & $1.2(1.1-1.4)$ & $71.5(70.2-72.8)$ & $1.3(1.1-1.4)$ \\
\hline No & $41.4(39.4-43.4)$ & 1.00 & $58.9(48.1-68.9)$ & 1.00 & $38.9(32.3-45.9)$ & 1.00 & $74.6(73.5-75.6)$ & 1.00 & $64.1(63.2-65.1)$ & 1.00 \\
\hline \multicolumn{11}{|c|}{ Population coverage of smoke-free laws ${ }^{c}$} \\
\hline $100 \%$ state laws & $48.7(46.4-51.1)$ & $1.2(1.0-1.4)$ & $65.3(52.1-76.5)$ & $2.9(1.1-7.4)$ & $37.3(29.8-45.5)$ & $0.5(0.3-0.9)$ & $77.0(75.9-78.0)$ & $1.2(1.1-1.3)$ & $68.1(67.1-69.2)$ & $1.1(1.1-1.3)$ \\
\hline 20-99\% state laws & $48.4(44.0-52.8)$ & $1.1(0.9-1.4)$ & $69.3(56.6-79.7)$ & $3.2(1.2-8.3)$ & $39.0(27.3-52.1)$ & $0.6(0.3-1.2)$ & $78.5(76.1-80.6)$ & $1.2(1.0-1.3)$ & $69.2(67.1-71.2)$ & $1.1(1.0-1.2)$ \\
\hline $1-19 \%$ state laws & $47.5(43.2-52.0)$ & $1.1(0.9-1.4)$ & $51.8(30.2-72.7)$ & $1.3(0.5-3.6)$ & $40.2(27.8-54.0)$ & $0.7(0.3-1.4)$ & $75.0(72.3-77.5)$ & $1.0(0.9-1.2)$ & $65.4(63.1-67.6)$ & $1.0(0.9-1.1)$ \\
\hline $0 \%$ state or local laws & $45.2(42.0-48.5)$ & 1.00 & $57.7(43.3-70.9)$ & 1.00 & $48.1(38.4-57.9)$ & 1.00 & $73.6(72.0-75.2)$ & 1.00 & $64.0(62.5-65.5)$ & 1.00 \\
\hline
\end{tabular}

Abbreviation: AOR adjusted odds ratio, Cl confidence interval, Al/AN American Indian/Alaska Native, NH/PI Native Hawaiian/Pacific Islander, GED Graduate Equivalency Degree, LGBT Lesbian, Gay, Bisexual, or Transgender ${ }^{a}$ Combustible only was defined as those who reported smoking at least 100 cigarettes during their lifetime and who currently smoke cigarettes, and/or use cigars/cigarillos/little cigars, pipes, water pipe/hookah, and do not use chewing tobacco/snuff/dip or snus. Noncombustible only was defined as those who reported using chewing tobacco/snuff/dip or snus on $\geq 1$ day during the past 30 days and do not currently smoke cigarettes, and/or use cigars/cigarillos/little cigars, pipes, water pipe/hookah. Combustible and noncombustible users are those who use both combustible and noncombustible tobacco products. No tobacco users are cigarettes, and/or use cigars/cigarillos/little cigars, pipes, water pipe/hookah. Combustible and noncombustible users are those who use both combustible and noncombustible tobacco products. No tobacco users are
those who do not currently use any combustible or noncombustible products ${ }^{b}$ Adjusted odds ratios were computed using a binary logistic regression model adjusted for all covariates listed in the table; additionally, tobacco use was included in the overall model. Statistically significant odds Adjusted odds ratios were computed using a binary logistic regression model adjusted for all covariates listed in the table; additionally, tobacco use was included in the overall model. Statistically significant odds
ratios are noted in bold. For tobacco use status in the overall model, the overall prevalence and adjusted OR for combustible only users was $47.9(46.2-49.5)$ AOR $=0.3(0.2-0.4)$; noncombustible only users was 62.1 ratios are noted in bold. For tobacco use status in the overall model, the overall prevalence and adjusted OR for combustible only users was $47.9(46.2-49.5)$ AOR $=0.3(0.2-0.4)$;
$(54.3-69.4), A O R=0.7(0.5-0.9)$; combustible and noncombustible users was $40.7(35.6-46.0)$, AOR $=0.3(0.2-0.4) ;$ and no tobacco users was $76.5(75.6-77.3)$, AOR $=1.00$ (referent) $(54.3-69.4), A O R=0.7(0.5-0.9)$; combustible and noncombustible users was $40.7(35.6-46.0)$, AOR $=0.3(0.2-0.4)$; and no tobacco users was $76.5(75.6-77.3)$, AOR $=1.00$ (referent)
'Population coverage of smoke-free laws was based on the ANRF's U.S. Tobacco Control Laws Database ${ }^{\Theta}$ and represents the percent of the population covered by state and/or local comprehensive smoke-free laws as of July 1,2010 'Relative SE $>30 \%$

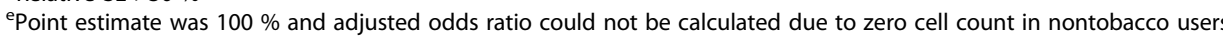


these states [3, 39]. Conversely, the relatively lower coverage in some states could be attributable to higher smoking rates or varying norms related to the social acceptability of tobacco use [40, 41]. Improving public awareness about the harms of SHS could help inform pathways to smoke-free policy implementation. The implementation of such policies could also further enhance public knowledge of the dangers of SHS and favorable attitudes towards smoke-free environments. The adoption of smoke-free policies have been shown to increase public favorability toward smoke-free environments in public and private settings [15, 42-45]. For example, Tang and colleagues found favorability toward smokefree bar law implantation among bar patrons and bar owners and staff [46]. Similarly, Fong and colleagues documented increased support for smoke-free environments following Ireland's implementation of comprehensive smoke-free legislation [15]. In the U.S., Cheng and colleagues documented positive associations between comprehensive smoke-free law adoption and voluntary smoke-free home rules [43]. Thus, opportunities exist for leveraging public attitudes toward SHS to promote smoke-free environments in states not protected by statewide comprehensive smoke-free policies.

Variations in harm perception were also observed by comprehensive smoke-free law coverage. A significant association was observed between perceptions about the harm of SHS exposure and population level coverage of state and/or local smoke-free laws, overall and by noncombustible only users, combustible and noncombustible users, and no tobacco users. In general, given that perceptions about the harm of SHS exposure were higher among respondents covered by a $100 \%$ smokefree law compared to those not covered by such a law, it is possible this result could be attributable to the changing social norms related to the social acceptability of tobacco use and the increased prevalence of smoke-free environments [47]. These findings underscore the importance of efforts to further increase public awareness of the health effects of SHS through education campaigns, which can contribute to changes in social norms regarding the acceptability of smoking around others.

The major strength of this study is that it utilized a large, nationally representative database and assessed factors associated with perceptions of harm across tobacco use categories and levels of smoke-free law coverage. However, the study is subject to at least eight limitations. First, these data are self-reported and may be subject to recall bias. Second, these data are crosssectional and, thus, it was not possible to assess causal relationships between harm perceptions and smoke-free law adoption. Third, the overall NATS response rate was $37.6 \%$ and state response rates ranged from 28.2 to $49.3 \%$; low response rates increase the potential for bias.
Fourth, in order to prevent large variances in survey estimates and small sample sizes, cellular telephone respondents were excluded from estimates for states that had fewer than 200 cellular telephone respondents. However, we included cellular telephone respondents in all national estimates and in estimates for the 12 states that had a sufficient sample size. Given that cellular phone only users are more likely to be current cigarette smokers, the omission of cellular phone only users could lead to overestimation of perceived harm from SHS for the remaining 38 states [48]. Fifth, the operational definition of perceived harm used in this study did not fully align with measures used elsewhere in the literature [49]. Moreover, the employed question asked about respondents' beliefs about breathing smoke from other people's cigarettes or from other tobacco products, and thus, it is not possible to determine if perception from cigarette smoke may have differed from other tobacco products. Sixth, these data are from 2009 to 2010, and thus, may not reflect more recent harm perceptions toward SHS. However, although some progress has been made in reducing secondhand smoke exposure since that period at the state and local levels, it is not expected that population-level perceptions would change considerably over this five year period. Seventh, it is possible that perceptions of harm from SHS were underestimated in states with a statewide smoke-free policy that was not classified as $100 \%$ smoke-free due to certain exemptions, but which still protect a large proportion of the state's population from SHS exposure; for example California has an exemption for enclosed public places and places of employment, and therefore is not categorized as have a comprehensive law. However, a supplementary analysis that treated California as having $100 \%$ coverage did not significantly impact the currently presented estimates. Finally, it was not possible to assess perceptions of harm by frequency of tobacco product use given the manner in which current use was assessed for most products in the survey; future research is critical to further explore potential associations between harm perceptions and frequency of use of all forms of tobacco used by U.S. adults.

\section{Conclusion}

This is the first study to assess levels of perceived harm from SHS exposure by tobacco use status and comprehensive smoke-free law coverage among a nationally representative sample of U.S. adults. The findings reveal that nearly two-thirds of all U.S. adults perceived SHS exposure to be 'very harmful'. Efforts to increase awareness about the harms of SHS exposure and the benefits of smoke-free environments may help inform efforts to protect all Americans from SHS exposure, particularly tobacco users. Variability in perceptions about the harm 
of SHS was observed by tobacco use status, with prevalence being highest among adults who do not use tobacco and lowest among those who use both combustible and noncombustible tobacco. Additionally, perceptions about the harm of SHS exposure were higher among respondents covered by a $100 \%$ smokefree law compared to those not covered by such a law. These findings underscore the importance of efforts to further increase public awareness of the health effects of SHS through education campaigns, which can contribute to changes in social norms regarding the acceptability of smoking around others. Efforts to educate the public about the dangers of SHS are especially important among tobacco users, particularly combustible only users and users of both combustible and noncombustible tobacco. Expanding comprehensive smoke-free policies could further protect all Americans from SHS, a completely preventable health hazard.

\section{Competing interest}

The authors declare they have no competing interest to report.

\section{Authors' contributions}

All authors contributed to the writing of this paper. JK drafted the manuscript. RP analyzed the data. JK, MK, SB, BK designed the study and interpreted the data. All authors approved the final version to be submitted for consideration of publication.

\section{Acknowledgements}

The findings and conclusions in this report are those of the authors and do not necessarily represent the official position of the Centers for Disease Control and Prevention. Funding for Dr. Michelle Kegler's contribution to this work was provided by the National Cancer Institute under the State and Community Tobacco Control Initiative, Grant Number U01-CA154282. There were no sources of funding, direct or indirect, for other authors in regards to the reported research.

\section{Author details}

'Office on Smoking and Health, National Center for Chronic Disease Prevention and Health Promotion, Centers for Disease Control and Prevention, Atlanta, GA, USA. ${ }^{2}$ Contractor Support for NCCDPHP/NGIS, Office on Smoking and Health, National Center for Chronic Disease Prevention and Health Promotion, Atlanta, GA, USA. ${ }^{3}$ Emory University, Rollins School of Public Health, Atlanta, GA, USA.

Received: 13 July 2015 Accepted: 26 January 2016

Published online: 02 February 2016

\section{References}

1. U.S. Department of Health and Human Services. The health consequences of involuntary exposure to tobacco smoke: A report of the surgeon general. Atlanta: Department of Health and Human Services, Centers for Disease Control and Prevention, Coordinating Center for Health Promotion, National Center for Chronic Disease Prevention and Health Promotion, Office on Smoking and Health; 2006.

2. U.S. Department of Health and Human Services. The health consequences of smoking - 50 years of progress: A report of the surgeon general. Atlanta: Department of Health and Human Services, Centers for Disease Control and Prevention, National Center for Chronic Disease Prevention and Health Promotion, Office on Smoking and Health; 2014.

3. CDC. State Tobacco Activities Tracking and Evaluation (STATE) System. [www.cdc.STATESystem]

4. American Nonsmokers' Rights Foundation. Local $100 \%$ smoke-free laws in all workplaces, restaurants, and bars: effective by year. [http://www.nosmoke.org/download.php?file=/pdf/current_smoke-free_ordinances_by_ year.pdf]
5. CDC. State smoke-free laws for worksites, restaurants, and bars-United States, 2000-2010. Morb Mortal Wkly Rep. 2011;60(15):472-5.

6. CDC. Vital Signs: Disparities in nonsmokers' exposure to secondhand smoke. Morb Mortal Wkly Rep. 2015;64(4):103-8.

7. Tan ASL, Bigman CA, Mello S, Sanders-Jackson A. Is exposure to e-cigarette communication associated with perceived harms of e-cigarette secondhand vapour? Results from a national survey of US adults. BMJ Open. 2015;5: e007134.

8. King BA, Dube SR, Babb SD. Perceptions about the harm of secondhand smoke exposure among U.S. middle and high school students: findings from the 2012 National Youth Tobacco Survey. Tob Induced Diseases. 2013;11:16.

9. Richardson A, Pearson J, Xiao H, Staigaitis C, Vallone D. Prevalence, harm perceptions, and reasons for using non-combustible tobacco products among current and former smokers. Am J Public Health. 2014; 104(8):1437-44.

10. Liu ST, Nemeth JM, Klein EG, Ferketich AK, Kwan M, Wewers ME. Risk perceptions of smokeless tobacco among adolescent and adult users and nonusers. J Health Communication. 2015;20(5):599-606.

11. Sami M, Timberlake DS, Nelson R, Goettsch B, Ataian N, Libao P, et al. Smokers' perceptions of smokeless tobacco and harm reduction. JPHP. 2012;33(2):188-201.

12. Li Q, Hyland A, O'Connor R, Zhao G, Du L, Li X, et al. Attitudes towards the extension of smoking restrictions to selected outdoor areas in Italy. Tob Control. 2012;21(1):59-62.

13. McMillen RC, Winickoff JP, Klein JD, Weitzman M. US adult attitudes and practices regarding smoking restrictions and child exposure to environmental tobacco smoke: changes in the social climate from 2000-2001. Pediatrics. 2003;112(1 Pt 1):e55-60.

14. Gallus S, Rosato V, Zuccaro P, Pacifici R, Colombo P, Manzari M, et al. Support for smoke-free policies among smokers and non-smokers in six cities in China: ITC China Survey. Tob Control. 2010;19 Suppl 2:40-46.

15. Fong GT, Hyland A, Borland R, Hammond D, Hastings G, McNeill A, et al. Reductions in tobacco smoke pollution and increases in support for smokefree public places following the implementation of comprehensive smokefree workplace legislation in the Republic of Ireland: Findings from the ITC Ireland/UK Survey. Tob Control. 2006;15(Suppl III):iii51-8.

16. Lazuras $L$, Rodafinos A, Eiser JR. Adolescents' support for smoke-free public settings: the roles of social norms and beliefs about exposure to secondhand smoke. J Adolesc Health. 2011;49(1):70-5.

17. Kandra KL, McCullough A, Ranney L, Goldstein AO. Support among middle school and high school students for smoke-free policies, North Carolina, 2009. Prev Chronic Dis. 2013;10:120135.

18. Borland R, Yong H, Siahpush M, Hyland A, Campbell S, Cummings K, et al. Support for and reported compliance with smoke-free restaurants and bars by smokers in four countries: findings from the International Control (ITC) Four Country Survey. Tob Control. 2006;15(Supple 3):iii23-41.

19. International Agency for Research on Cancer. Evaluating the Effectiveness of Smoke-free Policies. Lyon, France: World Health Organization Press; 2009.

20. CDC Fact Sheet. Smoke-free policies receive public support. [http://www. cdc.gov/tobacco/data_statistics/fact_sheets/secondhand_smoke/protection/ public_support/index.htm]

21. Hyland A, Higbee C, Borland R, Travers M, Hastings G, Fong G, et al. Attitudes and beliefs about secondhand smoke and smoke-free policies in four countries: Findings from the International Tobacco Control Four Country Survey. Nicotine Tob Res. 2009;11(6):642-9.

22. Halpern-Felsher BL, Rubinstein ML. Clear the air: Adolescents' perceptions of the risks associated with secondhand smoke. Prev Medicine. 2005;41(1):16-22.

23. Duaso M, De Irala J, Canga N. Employees' perceived exposure to environmental tobacco smoke, passive smoking risk beliefs and attitudes towards smoking: A case study in a university setting. Health Ed Res. 2006;21(1):26-33.

24. Conlisk E, Proescholdbell SK, Pan WK. Support for tobacco control policies among youth in North Carolina. North Carolina Med J. 2006;67(3):175-9.

25. Gilpin EA, White MM, Farkas AJ, Pierce JP. Home smoking restrictions: which smokers have them and how they are associated with smoking behavior. Nicotine Tob Res. 1999;1(2):153-62.

26. Kegler MC, Malcoe LH. Smoking restrictions in the home and car among rural Native American and white families with young children. Prev Med. 2002;35(4):334-42 
27. Quick BL, Bates BR, Romina S. Examining antecedents of clean indoor air policy support: Implications for campaigns promoting clean indoor air. Health Commun. 2009;24(1):50-9.

28. Rayens MK, Hahn EJ, Langley RE, Hedgecock S, Butle KM, GreathouseMaggio L. Public opinion and smoke-free laws. Policy Polit Nurs Pract. 2007;8(4):262-70.

29. Saad L. Slim majority in U.S. call secondhand smoke very harmful: Views differ between parents who smoke vs. don't smoke. The Gallup Organization. 2014. [http://www.gallup.com/poll/174833/smokers-continuedownplay-harm-secondhand-smoke.aspx]

30. CDC. National Adult Tobacco Survey. Historical NATS Data and Documentation. 2009-2010 National Adult Tobacco Survey Weighting Methodology Report; 2011. [http://www.cdc.gov/tobacco/data_statistics/surveys/nats/]

31. CDC, Office on Smoking and Health and ICF. 2009-2010 National Adult Tobacco Survey Methodology Report; 2011. [http://www.cdc.gov/tobacco/ data_statistics/surveys/nats/pdfs/methodology-report.pdf]

32. Council of American Survey and Research Organizations (CASRO). Code of standards and ethics for survey research. 2011. [https://c.ymcdn.com/sites/ www.casro.org/resource/resmgr/casro_code_of_standards.pdf for-surveyresearch-CASRO]

33. American Nonsmokers' Rights Foundation. U.S. Tobacco Control Laws Database. http://www.no-smoke.org/goingsmokefree.php?id=519

34. CDC. Impact of a national tobacco education campaign on weekly numbers of quitline calls and website visitors-United States, March 4-June 23, 2013. Morb Mortal Wkly Rep. 2013;63(37):763-7.

35. Moore GF, Holliday JC, Moore LAR. Socioeconomic patterning in changes in child exposure to secondhand smoke after implementation of smoke-free legislation in Wales. Nicotine Tob Res. 2011;13(10):903-10.

36. Mills LM, Semple SE, Wilson IS, MacCalman L, Amos A, Ritchie D, et al. Factors influencing exposure to secondhand smoke in preschool children living with smoking mothers. Nicotine Tob Res. 2012;14(12):1435-44.

37. Sims M, Mindell JS, Jarvis MJ, Feyerabend C, Wardle H, Gilmore A. Did smoke-free legislation in England reduce exposure to secondhand smoke among non-smoking adults? cotinine analysis from the health survey for England. EHP. 2012;120(3):425-30.

38. O'Connor R, McNeill A, Borland R, Hammond D, King B, Boudreau C, et al. Smokers' beliefs about the relative safety of other tobacco products: Findings from the ITC collaboration. Nicotine Tob Res. 2007;9(10):1033-42.

39. CDC. Comprehensive smoke-free laws-50 largest U.S. cities, 2000 and 2012. Morb Mortal Wkly Rep. 2012;61(45):914-7.

40. Francis JA, Abramsohn EM, Park HY. Policy-driven tobacco control. Tob Control. 2010;19 Suppl 1:116-20.

41. Zhang $X$, Cowling DW, Tang H. The impact of social norm change strategies on smokers' quitting behaviors. Tob Control. 2010;19(Supp 1):i51-5.

42. Tang H, Cowling DW, Lloyd JC, Rogers T, Koumjian KL, Stevens CM, et al. Changes of attitudes and patronage behaviors in response to a smoke-free bar law. Am J Public Health. 2003;93(4):611-7.

43. Cheng K, Glantz S, Lightwood J. Association between smoke-free laws and voluntary smoke-free home rules. Am J Prev Med. 2011;41(6):566-72.

44. Nagelhout B, Van den Putte B, de Vries $\mathrm{H}$, Crone M, Fong G, Willemsen M. The influence of newspaper coverage and a media campaign on smokers support for smoke-free bars and restaurants and on secondhand smoke harm awareness: Findings from the International Tobacco Control (ITC) Netherlands Survey. Tob Control. 2012;21(1):24-9.

45. Cheng KW, Okechukwu CA, McMillen R, Glantz SA. Association between clean indoor air laws and voluntary smoke-free rules in homes and cars. Tob Control. 2015;24(2):168-74

46. Tang H, Cowling DW, Stevens CM, Lloyd JC. Changes of knowledge, attitudes, beliefs, and preference of bar owner and staff in response to a smoke-free bar law. Tob Control. 2004;13(1):87-9.

47. Siahpush M, McNeill A, Hammond D, Fong GT. Socioeconomic and country variations in knowledge of health risks of tobacco smoking and toxic constituents of smoke: results from the 2002 International Tobacco Control (ITC) Four Country Survey. Tob Control. 2006;15(Suppl III):ii65-iii70.

48. Blumberg SJ, Luke JV. Wireless substitution: early release of estimates from the National Health Interview Survey, January-June 2010. Hyattsville, MD: Centers for Disease Control and Prevention, National Center for Health Statistics; 2010. [http://www.cdc.gov/nchs/data/nhis/earlyrelease/wireless201212.PDF].

49. Brewer NT, Weinstein ND, Cuite CL, Herrington JE. Risk perceptions and their relation to risk behavior. Ann Behav Med. 2004:27:125-30.

\section{Submit your next manuscript to BioMed Central and we will help you at every step:}

- We accept pre-submission inquiries

- Our selector tool helps you to find the most relevant journal

- We provide round the clock customer support

- Convenient online submission

- Thorough peer review

- Inclusion in PubMed and all major indexing services

- Maximum visibility for your research

Submit your manuscript at www.biomedcentral.com/submit
C Biomed Central 